\title{
Characteristics of Puberty Period in Adolescent Girls and Major Risk Factors of Menstrual Function Disorders Against the Background of Endemic Goiter
}

\author{
Svitlana Hafiichuk
}

\begin{abstract}
Disorders of menstrual function are often the result of thyroid dysfunction and disorders of the neuroendocrine regulation, initiated by iodine deficiency, and are the most destructive in puberty period.

The objective of the study was to clarify the peculiarities of establishment of menstrual function and the degree of interaction between the hypothalamic-pituitary-ovarian system and thyroid gland against the background of iodine deficiency in adolescence.

Materials and methods of research. Analytical analysis of medical records and sociomedical audit were carried out by interviewing 490 girls of puberty age, the purpose of which was to estimate the prevalence of thyroid dysfunction and possible factors of development of menstrual disorders.

Results of the study and their discussion. The proportion of thyroid dysfunction in adolescent girls is quite significant; hypofunction was diagnosed 3.4 times more frequent than its increased activity. Less than half of the studied had regular menstrual cycle, while girls with thyroid dysfunction suffered much more often from menstrual dysfunction in the form of hypomenstrual syndrome (1.5-fold, $p<0.05)$, algodismenorrhea (1.6-fold, $p<0.05)$ and amenorrhea (1.4-fold, $p<0.05)$, premenstrual syndrome and anovulatory conditions associated with polycystic ovary syndrome. Such somatic diseases as neuro-vegetative dysfunction, diseases of the gastrointestinal tract, chronic tonsillitis, frequent lacunar angina and acute respiratory viral diseases are common. Clinical manifestations included symptoms of thyroid hypofunction, androgen-associated dermopathy, hirsutism syndrome, and concomitant endocrine-associated pathology of the mammary glands (mastalgia, mastopathy, and galactorrhea).

Conclusions. The burden of perinatal history, the presence of thyroid pathology and other manifestations of metabolic and endocrine disorders in first-degree relatives are unfavourable prognostic factors of disorders of the menstrual cycle against the background of thyroid dysfunction. The findings obtained allow us to determine the leading risk factors for problematic menstruation establishment and menstrual disorders, especially when combined with thyroid dysfunction. Hypomenstrual syndrome and algodysmenorrhea, as well as manifestations of premenstrual syndrome and anovulatory cycles, belong to major disorders of the menstrual cycle in case of thyroid gland dysfunction.
\end{abstract}

\section{Keywords}

puberty; thyroid gland; diffuse endemic goiter; menstrual disorders

Ivano-Frankivsk National Medical University, Ukraine

Corresponding author: svitlanabodnar@ukr.net

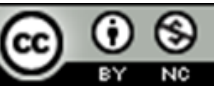




\section{Problem statement and analysis of the latest research}

According to a large amount of scientific studies, the proportion of girls with pathological puberty and menstrual dysfunction (MF) has increased in recent decades, which is a cause for concern and creates preconditions for reducing the reproductive potential of the female population $[5,6,1,2,3]$. It should be mentioned, that puberty period, the harmonious development of a girl, the state of her somatic health are decisive in the formation and establishment of possible predictors of disorders of menstrual and reproductive function. Disorders of the menstrual cycle (MC) are often a consequence of thyroid dysfunction; impaired neuroendocrine regulation, triggered by iodine deficiency, when the thyroid gland function decreases, the excretion of sex hormones, and hypothalamic-pituitary dysfunction are the most destructive in this period $[1,3,4,7]$.

The arguments presented, the study of the peculiarities of menstrual function establishment on the background of iodine deficiency, the definition of diagnostic criteria, the development of optimal preventive measures, both hormonal imbalance and combined metabolic disorders, as well as the introduction of clear practical recommendations, are a common problem of pediatric and adolescent gynecology which became the subject of this scientific research.

The objective of the study was to clarify the peculiarities of menstrual function establishment and the degree of interaction between the hypothalamic pituitary-ovarian system and thyroid gland against the background of iodine deficiency in adolescence.

\section{Materials and Methods}

Analytical analysis of medical records and sociomedical audit were performed by interviewing 490 adolescent girls, the purpose of which was to estimate the prevalence of thyroid dysfunction and the likely factors of development of menstrual disorders. Evaluation of questionnaires and medical records allowed to conduct in-depth analysis of the course of pre-puberty and puberty periods in girls aged 12 to 18 years with a comprehensive study of social factors, age of onset of menarche and first sexual debut, infectious factor, somatic and gynecological pathology, as well as clinical forms of thyroid dysfunction and the structure of menstrual disorders. The family history of somatic, endocrine and reproductive diseases of first-degree relatives (mother and daughter) was studied in detail. The sociological, clinical and anamnestic, anthropometric, instrumental and laboratory methods of research, as well as the mathematical and statistical methods, recommended for medical and clinical research, were used. Two study groups were formed and a clinical laboratory examination was performed in 210 patients aged 12 to 18 years, 120 of them had menstrual disorders against the background of thyroid dysfunction (first group). The second group included 60 girls with menstrual dysfunction and a healthy thyroid gland, 30 practically healthy girls comprised a control group. To determine the risk of developing pathological puberty, absolute and relative risk (OR) indicators, $95 \%$ confidence intervals $(95 \% \mathrm{CI})$, relative risk reduction, and informativeness of research were calculated.

\section{Results and Discussion}

According to the study, questionnaire, and medical records of 690 adolescents, the thyroid dysfunction was diagnosed in 251 patients $(36.4 \%)$, with 115 cases $(45.8 \%)$ of diffuse endemic goiter without change in gland activity, caused by endemic zone of residence; 72 girls (28.7\%) had hypothyroidism of varying degrees of severity; in 24 patients $(9.6 \%)$ increased thyroid function was revealed; autoimmune thyroiditis - in $21(8.4 \%)$, nodular goiter - in $19(7.6 \%)$. That is, the proportion of thyroid dysfunction in adolescent patients is quite significant; and thyroid hypofunction was found 3.4 times more frequent $(\mathrm{p}<0.05)$ than its increased activity.

469 girls (67.9\%) had menstrual dysfunction, 159 girls $(33.9 \%)$ had thyroid dysfunction, 108 patients $(67.9 \%)$ were diagnosed with diffuse endemic goiter without change in gland activity, 40 (25.1\%) teenagers had hypothyroidism and $11(6.9 \%)$ suffered from autoimmune thyroiditis.

We considered it expedient to analyze and study 


\section{Characteristics of Puberty Period in Adolescent Girls and Major Risk Factors of Menstrual Function Disorders Against the Background of Endemic Goiter - 3/5}

the role of hereditary factors in the formation of menstrual disorders against the background of thyroid dysfunction, as today there are many scientific studies evaluating the genetic determination of these abnormalities, but they are based only on the assessment of genealogical history $[1,2,3,4]$. Careful analysis revealed the following: the incidence of puberty pathology and menstrual disorders in the surveyed girls' families according to the $1^{\text {st }}-2^{\text {nd }}$ degree of affinity was $41.7 \%$, the frequency of thyroid pathology $-38.9 \%$, which is 3.1 times and 5.9 times higher than the indicators in the control group $(p<0.05)$. Data on disorders of menstrual function establishment confirmed associative dependence on the degree of affinity, especially on the maternal line. The findings are important in optimizing the girls' monitoring program and predicting reproductive health disorders.

An important characteristic of adolescent girls' health is their physical development indicators, which are closely linked to the processes of establishment of menstruation and reproductive function. Body mass index, which makes it possible to assess the harmony of physical development and the risk of possible metabolic disorders, is a clinically relevant anthropometric indicator. According to our studies, $66.7 \%$ of girls had some abnormalities: in $37.2 \%$ of cases underweight was found, $29.4 \%$ of girls were overweight; the largest proportion of patients with asthenic and hypersthenic body type was in the first group (36.6\% and $34.2 \%$, respectively), in the second group - with normostenic and asthenic type ( $41.7 \%$ and $38.3 \%$, respectively), while in the control group, the main proportion was represented by normostenic body type (86.7\%). Based on the obtained indicators, it is necessary to point out a significant increase of disharmonious and sharply disharmonious development (2.9 times against control data $(\mathrm{p}<0.05))$ in girls with MC disorders associated with thyroid dysfunction. It should be noted that the sexual development score was higher in girls with thyroid pathology, and only in $18.3 \%$ of cases there was a delay in sexual development (delay in mammary gland formation, thelarche - in every third girl (33.3\%) at 14 years, and in $18.8 \%$ of cases - at the age of 18 years), which is evidence of serious deviations.

During the study, the assessment of prevalence of MC disorders in girls of the selected cohort was evaluated. It should be noted that menstrual dysfunction was significantly more frequently observed in patients with thyroid dysfunction - in 109 patients $(90.8 \%)$, in contrast to the cohort of girls of the second group, where pathological puberty was noted in half of patients - in 53.3\% against the data in control - 93.3\%.

Regular menstrual cycles were observed in less than half of the teenage girls surveyed, while girls with thyroid dysfunction had menstrual dysfunction in the form of hypomenstrual syndrome much more often (1.5-fold, $\mathrm{p}<0.05)$, algodysmenorrhea (1.6fold, $\mathrm{p}<0.05$ ), and menorrhea (1.4-fold, $\mathrm{p}<0.05$ ); cases of premenstrual syndrome and anovulatory conditions, associated with PCOS, were twice the data in the case of normal thyroid function $(p<0.05)$.

A high index of somatic diseases, including neuro-vegetative dysfunction, diseases of the gastrointestinal tract, chronic tonsillitis, frequent lacunar angina and acute respiratory viral diseases, should be noted. Determining the dependence of possible risk factors on frequency of hormonal disorders in girls 12-18 years with disorders of MC, revealed a positive correlation with a high index of somatic pathology, primarily ENT organs ( $\mathrm{r}=$ $+0.91)$, thyroid dysfunction $(\mathrm{r}=+0.78)$, a body weight deficit $(r=+0.62)$ and overweight $(r=+$ $0.76)$, a high proportion of pathological puberty and late menarche $(\mathrm{r}=+0.41)$, and early sexual debut $(\mathrm{r}=+0.46)$.

Objective examination of girls with thyroid pathology and disorders of MC revealed a variety of clinical manifestations. The most common clinical manifestations in patients with thyroid pathology and MC disorders were: dry skin (46.7\%), mastopathy and mastalgia (32.5\% and $40.0 \%$, respectively), clinical symptoms of functional hyperprolactinemia (34.2\%), hyperkeratosis of the elbows and knees (36.7\%), androgen-associated dermopathy (35.8\%), as well as symptoms associated with thyroid hypofunction (chill, defective memory, overweight, constipation, etc.) in almost one-third of patients.

Thus, it can be assumed that morphofunctional 


\section{Characteristics of Puberty Period in Adolescent Girls and Major Risk Factors of Menstrual Function Disorders Against the Background of Endemic Goiter - 4/5}

formation of the reproductive system in girls with MC disorders is characterized by the deviations of anthropometric data, the formation of delayed sexual development in a third of patients and the disharmony of physical development. High proportion of untimely menarche (mainly delayed), menstrual establishment disorder with the most common clinical forms - algodysmenorrhea, hypomenstrual syndrome and amenorrhea, delayed formation of the breast, pubarche, indicating estrogen deficiency in patients of this cohort, should be taken into account.

The comparative analysis showed that the most severe negative impact on the formation and risk of menstrual disorders was due to factors such as hereditary predisposition to impaired reproductive function (OR-14.06; 95\% CI: 3.18-29.8), late menarche and pathological puberty (OR-3.25; 95\% CI: 0.84-5.68), thyroid dysfunction (OR-7.05; 95\% CI: 0.84-13.36) and a high index of somatic pathology (OR-6.86; 95\% CI: 1.26-14.12), metabolic disorders (overweight and low BMI) (OR-4.19; 95\% CI: 2.84-8.62), early sexual debut and early pregnancy interrupted by instrumental interventions (OR-3.05; 95\% CI: 0.34-8.57).

According to the results obtained at this stage of the scientific search using the analytical approach in the process of examination of a representative contingent of teenage girls with disorders of the menstrual cycle, it was possible to establish a significant prevalence of combined diseases of the thyroid gland (diffuse endemic goiter, autoimmune thyroiditis, subclinical hypothyroidism, etc.), and to evaluate the dominant components of the structure of menstrual function disorders (hypomenstrual syndrome, algodysmenorrhea, oligo- and amenorrhea). The data obtained are of some concern, since metabolic and endocrine disorders require appropriate correction and detailed approach, involving the advisory recommendations of pediatric and adolescent gynecologists, endocrinologists, and psychologists. This indicates the feasibility of scientific research in this area and the development of organizational programs to address the problem.

\section{Conclusions}

The burden of perinatal history, the presence of thyroid pathology and other manifestations of metabolic and endocrine disorders in first-degree relatives are unfavourable prognostic factors of disorders of the menstrual cycle in thyroid dysfunction including diffuse endemic goiter in girls of the studied cohort.

Hypomenstrual syndrome and allodysmenorrhea, as well as manifestations of premenstrual syndrome and anovulatory cycles, took the first place in the structure of menstrual cycle disorders in the case of thyroid gland dysfunction. Such clinical manifestations as thyroid hypofunction, androgenassociated dermopathy, hirsutism syndrome, and concomitant endocrine-associated pathology of the mammary glands (mastalgia, mastopathy, and galactorrhea), were predominant.

The results obtained at this stage of the research allow us to determine the leading risk factors for menstrual disorders, especially when combined with thyroid dysfunction which creates the preconditions for reduced reproductive potential in the future, as well as to make prognostic criteria, to develop a program of preventive measures and medication correction, and to optimize a girl's reproductive behaviour.

\section{Conflict of Interest}

The authors stated no conflict of interest.

\section{Financial Disclosure}

The authors declared no financial support.

\section{References}

[1] Bachynska IV, Havrylova IV. Osoblyvosti stanovlennia menstrualnoii funktsii u divchatok z patolohiieiu shchytovydnoii zalozy [Peculiarities of formation of menstrual function in girls with thyroid pathology]. Tavricheskiy mediko-biologicheskiy vestnik. 2011; 55: 29-32 (in Ukrainian).

[2] Boichuk AV, Petrenko NV. Osoblyvosti klinichnykh proiaviv alhodysmenoreii u molodykh 
divchat [Peculiarities of clinical manifestations of algodysmenorrhea in adolescent girls]. Bukovynskyi medychnyi visnyk. 2004; 8 (2): 22-25 (in Ukrainian).

[3] Vatseba AO, Pankiv VI. Chastota zakhvoriuvan shchytopodibnoii zalozy u Karpatskomu rehioni [Frequency of thyroid disease in the Carpathian region]. Ukraiinski medychni visti. 2007; 4 (1): 24 (in Ukrainian).

[4] Kokolina, VF. Detskaya i podrostkovaya ginekologiya [Pediatric and adolescent gynecology]. Medpraktika. 2012; 640 (in Russian).

[5] Brent GA, Larsen PR, Davies TF, Kronenberg HM, Melmed S, Polonsky KS, Karsen PR. Hypothyroidism and thyroiditis. Williams Textbook of Endocrinology, 11th ed., Philadelphia, Pa: Saunders Elsevier. 2008; Chap. 12.

[6] Danfeng Du, Xuelian Li, Clin J. The relationship between thyroiditis and polycystic ovary syndrome: a meta-analysis. Exp. Med. 2013; 6 (10): 880-889.

[7] Roti E, Vagenakis AG. Effects of iodide excess: clinical aspects. The thyroid. A fundamental and clinical text. Philadelphia: Lippincott-Raven. 2006; 316-327.

Received: $2020-05-04$

Revised: $2020-05-24$

Accepted: 2020-05-30 